\title{
APPLICATION OF A SURPLUS PRODUCTION MODEL TO ASSESS ENVIRONMENTAL IMPACTS ON EXPLOITED POPULATIONS OF DAPHNIA PULEX IN THE LABORATORY
}

\author{
A. L. JENSEN \\ School of Natural Resources, University of Michigan, Ann Arbor, Michigan 48109, USA
}

$\&$

J. S. Marshall

Ecological Sciences Section, Radiological and Environmental Research Division, Argonne National Laboratory, Argonne, Illinois 60439. USA

\begin{abstract}
The surplus production model is a simple and easily applied model for the assessment of environmental impacts on exploited fish populations. However, its application requires several assumptions about the relationships between the degree of impact and the population response that are difficult to test using field data. To examine these assumptions, the model is applied to exploited laboratory populations of Daphnia pulex exposed to chronic radiation stress. The model describes the observed relationship between equilibrium population size and the level of radiation exposure. It also describes the relationship between yield and population size.
\end{abstract}

\section{INTRODUCTION}

In order to assess environmental impacts it is often necessary to apply a mathematical model to estimate the population size and to simulate impacts. The surplus production model, which has often been applied for the assessment of fisheries, is also useful for the assessment of environmental impacts on fish populations. The surplus production model is simple and easily modified to incorporate environmental impacts and its parameters can be estimated using catch and effort data that are frequently available for exploited fish populations. The surplus production model was developed for fish stock assessment by Volterra (1928), Hjort et al. (1933) and Graham (1935), and has been widely applied (Schaefer, 1957; Ricker, 1975; Jensen, 1976, 1978). This model has also been applied 273

Environ. Pollut. Ser. A. 0143-1471/82/0028-0273/\$02.75 C Applied Science Publishers Ltd, England, 1982 Printed in Great Britain 
to assess the impact of power plant entrainment and impingement on fish populations and commercial fisheries (Jensen et al., 1982). It is especially well suited for the rapid identification of potentially serious impacts.

The model's assumptions cannot be tested when it is applied for impact assessment and the accuracy of its predictions can seldom be determined. Laboratory studies are necessary to demonstrate that the model provides a reasonable description of the response of exploited populations to environmental stress. Silliman (1971) applied the model to exploited fish populations in the laboratory and demonstrated that it accurately describes the response of a laboratory population to exploitation. In our study the surplus production model is applied to describe the response of exploited Daphnia pulex populations to chronic radiation stress. The model is applied to describe the relationship between yield and population size at different radiation doses, and the maximum sustainable yield is formulated in terms of the level of exposure.

\section{MODEL DEVELOPMENT}

Fish populations are separated into two components for assessment: a group susceptible to the fishing gear, termed the recruited stock, and a group that is not vulnerable to the gear and is usually composed of younger individuals. Models are developed to describe the dynamics of the recruited portions of the stocks. The relationship between the fishing mortality-i.e. the yield to the fishermen- $\mathrm{d} Y / \mathrm{d} t$, and population size is modelled as $\mathrm{d} Y / \mathrm{d} t=q E N=F N$, where $q$ is a catchability coefficient, $E$ is fishing effort, $N$ is population size and $F$ is the instantaneous fishing mortality coefficient. This equation assumes that fishing mortality per individual is proportional to fishing effort. The probability of capture is the same for all members of the population and each additional unit of effort is as effective as the rest.

A similar approach can be applied to model environmental impacts. The death rate of recruited individuals resulting from an environmental stress, $\mathrm{d} D / \mathrm{d} t$, can be modelled as $\mathrm{d} D / \mathrm{d} t=h\left(C-C_{0}\right) N$, where $C$ is the level of stress, $C_{0}$ is a threshold level and $h$ is a parameter that measures the lethality of the stress. This equation assumes that mortality per individual is proportional to the level of stress and that each individual has the same probability of death from the environmental stress. More detailed models could be developed in which age structure or some other basis is applied to obtain a range of susceptibilities within the population. Also, for toxic stress it might be more realistic to apply the model $\mathrm{d} D / \mathrm{d} t=h \ln \left(C-C_{0}\right) N$, which assumes that the distribution of tolerance within the population is not symmetrical. For simplicity, the same model structure as applied for fishery assessment was applied for the assessment of environmental stress. This approach should be adequate for the identification of serious impacts. If such an impact is detected, a more detailed analysis, probably including the application of an age structure model, would then be necessary in order to quantify the impact. 
The above relationship between mortality and stress also applies to environmental impacts that act on individuals not recruited into the fishery, such as eggs, larvae and juveniles, if it is assumed that egg production is proportional to the biomass of the recruited stock (Jensen et al., 1982).

The surplus production model assumes that a population has some capacity to increase and that this capacity is a function of population size. Several models have been proposed to relate the capacity to increase to population size. The earliest and most commonly applied model assumes that the relationship between the capacity to increase and population size is a parabola (Volterra, 1928; Hjort et al., 1933; Graham, 1935; and Schaefer, 1957). A model developed more recently gives a curve with a long tail towards the right (Fox, 1970), as has been observed in some fisheries, and a flexible curve has been developed that can take many different shapes (Pella \& Tomlinson, 1969). However, the shape of the relationship between the capacity to increase and population size is difficult to determine and, because of its simplicity, the parabola remains the most frequently applied curve.

In this study the parabola is used; so the surplus production model, modified for the impact of an environmental stress, is:

$$
\begin{aligned}
\frac{\mathrm{d} Y}{\mathrm{~d} t} & =F N=q E N \\
\frac{\mathrm{d} D}{\mathrm{~d} t} & =h\left(C-C_{0}\right) N \\
\frac{\mathrm{d} N}{\mathrm{~d} t} & =r N-\frac{r}{K} N^{2}-F N-h\left(C-C_{0}\right) N
\end{aligned}
$$

where $Y$ is yield from the exploited population; $F$ is the instantaneous fishing mortality coefficient; $q$ is the catchability coefficient; $E$ is the fishing effort; $N$ is the population size in numbers; $D$ is the number of deaths induced by the environmental stress; $h$ is the environmental stress mortality coefficient; $C$ is the level of the environmental stress; $C_{0}$ is the threshold environmental stress level; $r$ is the innate capacity for increase and $K$ is the average population size without exploitation or environmental stress. The measure of environmental stress can be any of a diverse array of factors such as volume flow at a power plant for the assessment of entrainment and impingement impacts, concentration of a toxicant for toxicity assessment or level of radiation exposure.

Several relations of interest are obtainable from the model. For values of $F$ and $C$ such that:

$$
F+h\left(C-C_{0}\right)<r
$$

The population will approach an equilibrium where $\mathrm{d} N / \mathrm{d} t=0$. The equilibrium population size is:

$$
N_{e}=K-\frac{K}{r} F-\frac{K h}{r}\left(C-C_{0}\right)
$$


The impact of the environmental stress on equilibrium yield, $Y_{e}$, is given by the parabola:

$$
Y_{e}=r N-\frac{r}{K} N^{2}-h\left(C-C_{0}\right) N
$$

The maximum sustainable yield occurs at a population size of:

$$
N=\frac{K}{2}-\frac{h\left(C-C_{0}\right) K}{2 r}
$$

Substitution of eqn.(5) into eqn.(4) gives the following relationship between maximum sustainable yield $(M S Y)$ and the level of environmental stress:

$$
M S Y=\frac{r K}{4}-\frac{h\left(C-C_{0}\right) K}{2}-\frac{h^{2}\left(C-C_{0}\right)^{2} K}{4 r}
$$

Comparing eqns (3), (4) and (6) with the observed results provides a basis for the evaluation of how well the model describes the response of an exploited population to environmental stress.

\section{EXPERIMENTAL METHODS}

The experimental methods are described in detail by Marshall (1967) and are reviewed here only briefly. A $4 \times 4$ factorial experiment was carried out in which four exploitation rates and four levels of radiation exposure were applied to thirtytwo laboratory Daphnia pulex populations (Table 1). Each of the sixteen treatment combinations was replicated twice. When extinction occurred in the populations under the two highest exploitation rates, they were restarted. The exploitation rates used were $15 \%, 40 \%, 65 \%$ and $90 \%$ a week, which were equivalent to instantaneous fishing mortality rates of $0.16,0.51,1.05$ and 2.30 a week.

The radiation exposures were administered by placing the cultures at different distances from a 30 -curie ${ }^{60} \mathrm{Co}$ source. The exposure rates varied during the experiment (Marshall, 1967); for application of the model the average level of exposure was applied.

\section{RESULTS AND DISCUSSION}

For application of the model to fisheries the parameters are estimated using catch and effort data (Gulland, 1969; Ricker, 1975; Jensen et al., 1982). This approach requires the assumption that catch per unit of effort is proportional to biomass and requires least squares estimation of a set of highly correlated parameters. With field 
TABLE 1

RADIATION EXPOSURE, EXPLOITATION RATES, $F$; AVERAGE YIELD PER WEEK (NUMBERS), $Y$; AND A VERAGE SIZE OF Daphnia POPULATIONS, $N$

\begin{tabular}{ccrr}
\hline$R /$ day & $\mathrm{F}$ & $\mathrm{Y}$ & $\mathrm{N}$ \\
\hline $4 \cdot 4$ & $0 \cdot 16$ & 30 & 188 \\
135 & $0 \cdot 16$ & 25 & 156 \\
324 & $0 \cdot 16$ & 23 & 144 \\
546 & $0 \cdot 16$ & 13 & 81 \\
$4 \cdot 4$ & $0 \cdot 51$ & 87 & 171 \\
135 & $0 \cdot 51$ & 79 & 155 \\
324 & $0 \cdot 51$ & 61 & 120 \\
546 & $0 \cdot 51$ & 29 & 57 \\
$4 \cdot 4$ & $1 \cdot 05$ & 136 & 130 \\
135 & $1 \cdot 05$ & 134 & 128 \\
324 & $1 \cdot 05$ & 87 & 83 \\
546 & $1 \cdot 05$ & 43 & 41 \\
$4 \cdot 4$ & $2 \cdot 30$ & 126 & 55 \\
135 & $2 \cdot 30$ & 81 & 35 \\
324 & $2 \cdot 30$ & 63 & 27 \\
546 & $2 \cdot 30$ & 27 & 12
\end{tabular}

data, accurate estimation of parameters is difficult and uncertain (Schnute, 1977; Uhler, 1980). In this study abundance was measured directly and eqn. (3) was fitted by least squares. The resulting parameter estimates are $K=192$ individuals, $r=3.7$ per week and $h=0.003$ per week. The regression was significant $(p<0.0001)$ and the coefficient of determination was high $\left(R^{2}=0.94\right)$. The equilibrium population sizes predicted using eqn. (3) are close to the observed values over the entire range of observations (Fig. 1). The model appears to fit the data somewhat better at higher population densities. Continuous time models provide a good approximation only

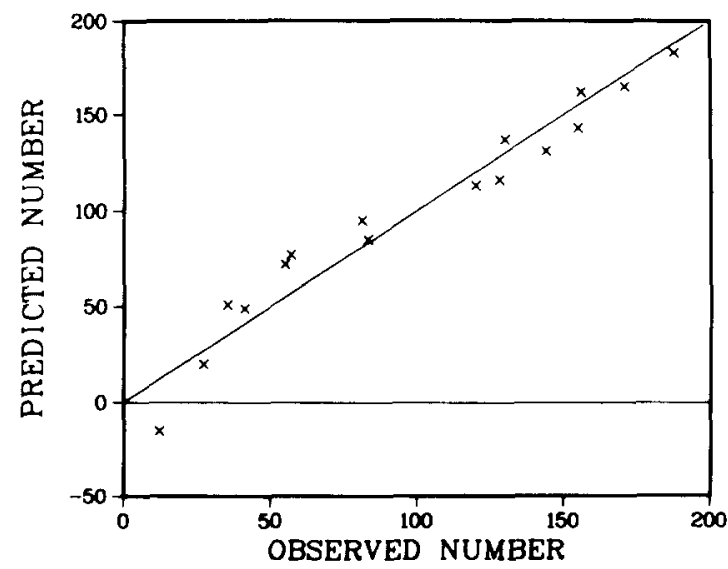

Fig. 1. Relationship between observed equilibrium population size and equilibrium population size predicted by the model. The line indicates perfect prediction and is not a fitted regression line. 
when population sizes are large and fluctuations resulting from the discrete nature of the populations are less noticeable; this may be the reason for the better fit at higher population densities.

The calculated parabolas relating yield to population size fit the trends in the observed data well (Fig. 2). At each level of radiation exposure, as the rate of

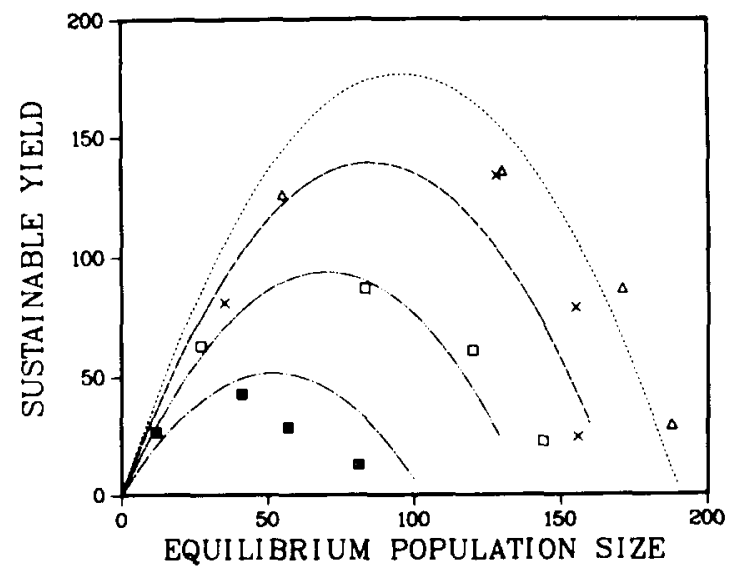

Fig. 2. Observed and predicted relationships between yield and equilibrium population size at four different levels of radiation exposure. From the top: $4.4 \mathrm{R} /$ day, $\triangle ; 135 \mathrm{R} /$ day, $x ; 324 \mathrm{R} / \mathrm{day}, \square$; 546R/day, 区.

exploitation increases the equilibrium population size decreases and the yield increases to a maximum and then begins to decrease. The data are not adequate enough to determine how closely the relationship between yield and population size is described by a parabola, but the general shape of the curve is correct; as population size decreases, the capacity to increase increases to a maximum and then begins to decrease. If the points are connected, two of the curves appear skewed towards the left ( $324 \mathrm{R} /$ day and $548 \mathrm{R} /$ day) and two of the curves appear skewed somewhat to the right ( $135 \mathrm{R} /$ day and $4.4 \mathrm{R} /$ day). It is possible that the shape of the curves depends on the level of stress but the data are not adequate enough to test this hypothesis. All of the data are described reasonably well by parabolas.

The observed yields are close to the calculated yields at radiation levels of $135 \mathrm{R} /$ day and $324 \mathrm{R} /$ day. At $4.4 \mathrm{R} /$ day the yield at the highest exploitation rate is well below that calculated from the model. At $548 \mathrm{R} /$ day the model does not accurately describe the observed stock production relationship. The parabola fits the data well enough for the detection of potentially serious environmental impacts. The relationship between the maximum sustainable yield and the level of radiation stress predicted by the model is shown in Fig. 3. As the level of radiation stress increases, the maximum sustainable yield decreases asymptotically to zero.

The model assumes that populations have a capacity to compensate for 


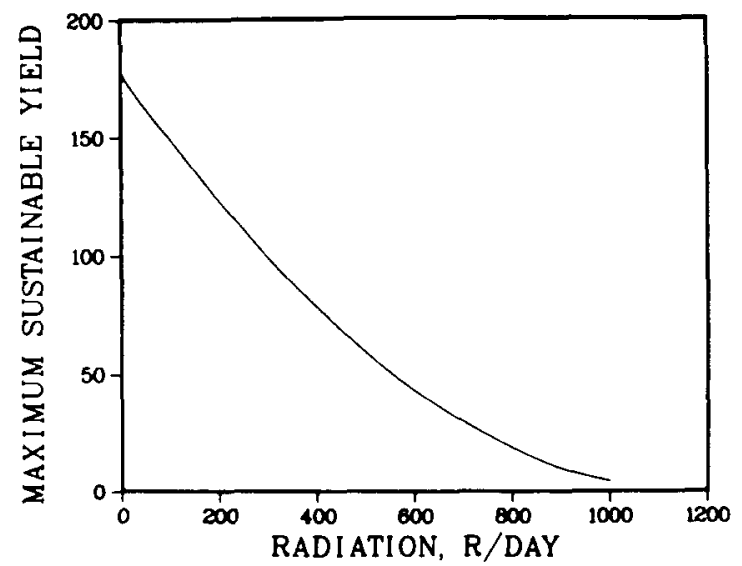

Fig. 3. Simulated relationship between maximum sustainable yield and level of exposure to radiation.

environmental stress and that populations possess a degree of resilience. The model does not describe the actual mechanisms of compensation and only indicates that, as the mortality rate increases, population size decreases and the rate of population growth increases to a maximum and then decreases. Many observations of exploited populations indicate that this is a realistic description of changes that occur with exploitation (Jensen, 1971; Ricker, 1975; McFadden, 1977). Similar changes occur when fish populations are exposed to heavy metal stress (McFadden \& Franzin, 1978). When Daphnia galeata mendotae populations were exposed to increasing cadmium concentrations the death rates increased and population sizes decreased, but over a wide range of cadmium concentrations the birth rates increased and the populations attained equilibrium at lower population sizes (Marshall, 1978). The higher death rates were balanced by higher birth rates.

Lack of a detailed mechanistic description of compensation within the model is both a strength and a weakness. Because the model does not describe the mechanisms in detail it has wide applicability but, even when the model fits well, it does not indicate how a population compensates for increased mortality and it gives little understanding of the underlying process. Yet the model can be useful for the detection of environmental stress.

The model describes the impacts of exploitation and exposure to radiation acting simultaneously and these two factors have different modes of impact. In the mortality model the mortality rates are additive. There is no direct interaction between these two sources of mortality. An increase in the exploitation coefficient, $F$, does not change the radiation-induced mortality coefficient, $h$. However, an increase in fishing effort reduces the population size, $N$, and this decreases the rate of radiation mortality because both exploitation and radiation-induced mortality are functions of population size. 
The logistic model gave an adequate description of the laboratory data but more complete and larger experiments are necessary for a more careful description of the relationship between the capacity to increase and population size, and the compensatory response of Daphnia populations.

\section{ACKNOWLEDGEMENTS}

The work reported in this paper was performed under the auspices of the United States Environmental Protection Agency (A.L.J.) and whilst one of the authors (J.S.M.) was on sabbatical leave at Argonne National Laboratory.

\section{REFERENCES}

Fox, W. W. (1970). An exponential yield model for optimizing exploited fish populations. Trans. Am. Fish. Soc., 99, 80-8.

Graham, M. (1935). Modern theory of exploiting a fishery and application to North Sea trawling. $J$. Cons. int. Explor. Mer., 10, 264-74.

Gulland, J. A. (1969). Manual of methods for fish stock assessment, Part I. Fish population analysis. FAO Manuals in Fishery Science, No. 4.

HJORT, J., John, G. \& OTTESTAD, P. (1933). The optimum catch. Hvalradets Skr., 7, 92-127.

JENSEN, A. L. (1971). Response of brook trout (Salvelinus fontinalis) populations to a fishery. J. Fish. Res. Bd Can., 28, 458-60.

Jensen, A. L. (1976). Assessment of the United States lake whitefish fisheries of Lake Superior, Lake Michigan, and Lake Huron. J. Fish. Res. Bd Can., 33, 747-59.

Jensen, A. L. (1978). Assessment of the lake trout fishery in Lake Superior: 1929-1950. Trans. Am. Fish. Soc., 107, 543-9.

Jensen, A. L., Spigarelli, S. A. \& Thommes, M. M. (1982). Application of conventional fishery models for assessment of entrainment and impingement impacts on three Lake Michigan fish species. Trans. Am. Fish. Soc., 111, 23-37.

Marshall, J. S. (1967). Radiation stress in exploited Daphnia populations. Limnol. Oceanogr., 12, 154-8.

Marshall, J. S. (1978). Population dynamics of Daphnia galeata mendotae as modified by chronic cadmium stress. J. Fish. Res. Bd Can., 35, 461-9.

MCFADDEN, J. T. (1977). An argument supporting the reality of compensation in fish populations and a plea to let them exercise it. In Assessing the effects of power plant-induced mortality on fish populations, ed. by W. Van Winkle, 153-83. New York, Pergamon Press.

MCFADDEN, G. A.\& FrANZIN, W. G. (1978). Elevated heavy metals: A stress on a population of white suckers, Catostomus commersoni, in Harnell Lake, Saskatchewan. J. Fish. Res. Bd Can., 35, 963-70.

Pella, J. J. \& Tomlinson, P. K. (1969). A generalized stock production model. Bull. Inter-Am. Trop. Tuna Commn, 13, 419-96.

RICKER, W. E. (1975). Computation and interpretation of biological statistics of fish populations. Bull. Fish. Res. Bd Can., 191, 382.

SCHAFFER, M. B. (1957). A study of the dynamics of the fishery for yellowfin tuna in the eastern tropical Pacific Ocean. Bull. Inter-Am. Trop. Tuna Commn, 2, 247-68.

SCHNUTE, J. (1977). Improved estimates from the Schaefer production model: Theoretical considerations. J. Fish. Res. Bd. Can., 34, 583-603.

SILliman, R. D. (1971). Advantages and limitations of 'simple' fishery models in light of laboratory experiments. J. Fish. Res. Bd Can., 28, 1211-14.

UHLER, R. S. (1980). Least squares regression estimates of the Schaefer production model: Some Monte Carlo simulation results. Can. J. Fish. Aquat. Sci., 37, 1284-94.

VOLTERRA, V. (1928). Variations and fluctuations of the number of individuals in animal species living together. J. Conseil. Explor. Mer., 3, 1-51. 